\title{
THE LOVE LETTER
}

This is not a love-letter.

I have put you out of my mind.

It is to fill you up

Until you vomit.

You are a mail-box.

I am snow.

\section{W O R D}

Dead flowers

for sick people

words cannot express

\author{
A D I N F I N I T U M \\ i am your first nude \\ man be sure you get \\ my poem in your \\ picture your picture \\ is in my poem \\ etcetera
}

\section{O F U S}

Afterwards the sheets

That smell of you you

Tell me smell of me.

what is the color of the rope round your neck 